\title{
PEMBELIAN IMPULSIF SELAMA PANDEMI COVID-19: MODEL MEDIASI
}

\author{
Hanny Lubaba ${ }^{1}$, Masyhuri ${ }^{2}$ \\ 1,2Universitas Brawijaya Malang, Lubaba123@ student.ub.ac.id; 22002081017@unisma.ac.id
}

\begin{abstract}
ABSTRAK
Penelitian ini bertujuan untuk menguji pengaruh visual merchandising terhadap pembelian impulsif yang dimediasi oleh emosi positif pada Toko Miniso Malang. Sampel penelitian ini adalah 100 pelanggan dari Toko Miniso Malang. Kuesioner digunakan untuk memperoleh jawaban responden tentang variabel cyang diteliti dengan menggunakan purposive sampling. Data dianalisis menggunakan pemodelan persamaan struktural menggunakan partial least square (PLS 3.0), yang kemudian digunakan untuk menjawab hipotesis penelitian. Hasil penelitian menemukan bahwa visual mmerchandising tidak berpengaruh signifikan terhadap pembelian impulsif, visual merchandising berpengaruh signifikan terhadap emosi positif, dan emosi positif memediasi visual merchandising terhadap pembelian impulsif. Adanya emosi positif akan turut meningkatkan pembelian impulsif, sehingga elemen emosi positif harus ditampilkan di dalam toko. Munculnya emosi positif dapat dilakukan dengan cara memaksimalkan kondisi internal gerai seperti faktor kenyamanan, keindahan dan tata letak yang menarik.
\end{abstract}

Kata Kunci: Visual merchandising, emosi positif, pembelian impulsif

\begin{abstract}
This study aims to examine the effect of visual merchandising on impulse buying mediated by positive emotion at Miniso, Malang Store. The sample was 100 customers of Miniso, Malang Store. Questionnaires are used to obtain respondents' answers about the variables studied by using purposive sampling. The data were analyzed using structural equation modeling using partial least square (PLS 3.0), which was then used to answer the research hypotesis. The study found visual merchandising has not a significant effect on impulse buying, visual merchandising has a significat effect on positive emotions, and positive emotion mediates visual merchandising on impulse buying. The presence of positive emotions will also increase impulse buying, so elements of positive emotions must be displayed in the store. The emergence of positive emotions can be done by maximizing the internal conditions of the outlets such as comfort, beauty and attractive layout factors.
\end{abstract}

Keywords: Visual merchandising, positive emotion, impulse buying.

Naskah diterima : 07-06-2021, Naskah dipublikasikan : 28-09-2021 


\section{PENDAHULUAN}

Pandemi covid-19 menjadi sebuah kondisi yang membuat negara di seluruh dunia mengalami krisis ekonomi, salah satunya Indonesia. Perekonomian Indonesia yang terus turun sampai kuartal ke III tahun 2020 3,49\% membuat dunia bisnis menjadi lesu (knks.go.id). Berbagai kebijakan pemerintah yang mengharuskan bekerja dari rumah, belajar melalui online serta adanya pembatasan kegiatan masyarakat membuat pebisnis harus berfikir lebih keras mengenai strategi yang diterapkan agar bisnis tidak gulung tikar. Termasuk bisnis ritail, Kandampully et al. 2018 mengatakan bahwa pengalaman pelanggan mencakup setiap momen kebenaran di mana pelanggan berinteraksi dengan perusahaan, produk atau layanan, pengaturan pengalaman pelanggan harus memerlukan strategi bisnis yang menghasilkan hubungan yang saling menguntungkan antara perusahaan dan pelanggannya. Ritail didefinisikan sebagai rangkaian aktivitas bisnis dengan menambahkan nilai suatu produk serta pelayanan kepada pelanggan dalam memenuhi kebutuhan sehari-hari.

Berdasarkan hasil survei dari Global Economic Monitor World Trend, pertumbuhan penjualan ritail di Indonesia berada pada angka -16,5 pada 2021 kuartal II, setelah sebelumnya berada pada kisaran -16,4\% pada 2021 kuartal I. Hal ini disebabkan terjadinya pandemi covid19 mulai awal tahun 2020 yang membuat seluruh kegiatan bisnis mengalami penurunan dari tahun ke tahun, tahun 2020 merupakan kondisi ritel terendah yang pernah terjadi di Indonesia (ceicdata.com).

Sebuah proses pengambilan keputusan untuk membeli secara cepat dari seorang konsumen dikenal sebagai pembelian impulsif (Husnain dan Waheed, 2016). Keputusan cepat untuk membeli produk setelah dipengaruhi oleh berbagai faktor di dalam toko dan juga stimulasi kesenangan atau kesenangan (Dey dan Srivastava, 2017). Untuk aspek lebih lanjut dari pembelian impulsif, empat domain dijelaskan. Yang pertama adalah membeli produk tanpa persiapan yang sedikit tepat. Kedua, membeli produk karena adanya faktor pendorong seperti harga, barang, dan desain produk. Ketiga, mendapatkan produk tanpa informasi, alternatif, dan nilai produk itu. Keempat, membeli produk di bawah bujukan apa pun atau secara psikologis antar muka (Lim et al, 2015). Variabel yang dapat meningkatkan pembelian impulsif adalah visual merchandising (Jain et al, 2012) lebih jauh lagi, dikatakan bahwa proses tampilan visual merchandising sering terjadi disebut sebagai "penjual diam" siapa memberikan informasi melalui media visual dan bernada jual atau saran untuk menambahkan barang untuk dibeli konsumen.

Visual merchandising adalah wiraniaga yang tidak berbicara tetapi dapat menyampaikan secara definitif pesan penjualan melalui stimulasi visual. Visual merchandising adalah sebuah teknik dalam menghadirkan tampilan yang menarik untuk pelanggan potensial. Visual merchandising dapat berfokus pada warna dan bagian-bagian asesoris. Visual merchandising adalah bagian dari bauran pemasaran ritel. Selain itu visual merchandising diartikan sebagai usaha dalam memusatkan perhatian konsumen agar terfokus pada presentasi produk yang disajikan ditempat penjualan (BBM, 2013). Selain visual merchandising, emosi positif juga mempengaruhi pembelian impulsif (Pramestya \& Widagda, 2020). Emosi adalah faktor penentu dan perantara yang akan menimbulkan keinginan pelanggan untuk berbelanja secara impulsif. Pengaruh emosional positif adalah tingkat di mana seseorang merasa antusias dan terinspirasi (Bismo et al., 2020).

Penelitian terdahulu ditemukan bahwa visual merchandising mempengaruhi keputusan impulsif (Diah Anggraini \& Sulistyowato, 2020; Mutiah 2018; Nurudin, 2020; Pancaningrum, 2017). Akan tetapi berbeda dengan hasil penelitian dari Kertiana \& Artini, (2019) yang menyebutkan secara jelas bahwa visual merchandising belum mampu meningkatkan pembelian impulsif. Sehingga, terjadi sebuah gap penelitian yang disebabkan oleh hasil yang tidak 
konsisten dari peneliti sebelumnya. Selanjutnya Penelitian terdahulu mengenai visual merchandising yang mengakibatkan muncul emosi positif dari konsumen (Andani \& Wahyono, 2018; Devi \& Nurcaya, 2020; Fatma, 2020).

Penelitian ini memiliki kebaruan yang menarik untuk diteliti, yaitu pengujian ulang peran variabel mediasi emosi positif antara visual merchandising dan pembelian impulsif. Oleh karena itu, hasil temuan ini agar menjadi salah satu pertimbangan dalam pengambilan keputusan strategi yang akan diterapkan dalam industri ritail, agar dapat bersaing dalam hal pemasaran serta dapat menjadi evaluasi bagi pihak Miniso dalam menyusun strategi pemasarannya ke depan.

\section{KAJIAN LITERATUR}

\section{Visual Merchandising}

Visual merchandising adalah suatu cara untuk merepresentasikan produk suatu merchandise yang dapat memikat serta dipersembahkan untuk calon konsumen (Sudarsono, 2017). Penelitian terdahulu ditemukan bahwa visual merchandising mempengaruhi pembelian impulsif (Diah \& Sulistyowati, 2020; Mutiah \& Munir, 2018; Nurudin, 2020; Pancaningrum, 2017). Kecenderungan konsumen membeli tanpa rencana, kemampuan konsumen dalam mengendalikan diri, dorongan yang kuat untuk segera membeli, dan kepedulian akibat yang akan terjadi setelah melakukan pembelian menyebabkan adanya peningkatan pembelian impulsif (Firdayanti et al., 2020).

\section{Emosi Positif}

Emosi positif cenderung lebih bertanggung jawab untuk membuat pelanggan lebih impulsif (Shirmohammadi et al., 2015). Lebih lanjut emosi dan hasil kognitif dari toko online bisa mempengaruhi keputusan pembelian yang tidak direncanakan (Liao et al., 2016).

\section{Pembelian Impulsif}

Pembelian impulsif dapat terjadi pada suatu produk, parfum, pakaian, make-up dan banyak lagi. Pembelian impulsif terjadi ketika seseorang memiliki keterlibatan berbasis mode dengan tren mode (Kinasih \& Jatra, 2018). Selanjutnya keinginan untuk melakukan pembelian sering muncul ketika mengunjungi toko atau mall (Deviana \& Giantari, 2016).

\section{Pengembangan Hipotesis \\ Visual Merchandising and Emosi Positif}

Sari \& Suryani (2014) menyatakan bahwa visual merchandising merupakan tampilan merchandise yang baik dan memiliki daya tarik pada aspek aksesoris, warna, dan aspek pendukung lainnya dengan tampilan yang sesuai secara langsung berpengaruh terhadap meningkatnya pembelian impulsif. Penelitian ini berpendapat bahwa jika semakin baik visual merchandising yang diterapkan oleh sebuah toko dapat mempengaruhi pembelian impulsif calon pelanggan yang melihatnya. Jadi, hipotesis yang diajukan adalah sebagai berikut:

H1: Visual merchandising berpengaruh positif dan signifikan terhadap emosi positif

\section{Emosi Positif dan Pembelian Impulsif}

Kemungkinan terjadinya emosi positif tergantung dari rangsangan yang disajikan pemilik bisnis agar dapat memberikan pengalaman positif yang berdampak pada emosi atau perasaan pelanggan (Soodan \& Pandey, 2016). Menurut Anggriawan et al., (2016) jika pelanggan memiliki pengalaman yang baik yang berdampak pada emosi, maka emosi itu mampu untuk merangsang pelanggan untuk memutuskan untuk membeli tanpa ada rencana atau spontan. Namun, jika pengalaman yang didapat pelangga negatif maka pelanggan cenderung 
untuk tidak melakukan aktivitas pembelian. Jadi, hipotesis yang diajukan adalah sebagai berikut:

$\mathrm{H} 2$ : $\quad$ Emosi positif berpengaruh positif dan signifikan terhadap pembelian impulsif

\section{Pengaruh dari Emosi Positif yang Memediasi Visual Merchandising dan Pembelian Impulsif}

Peneliti ingin mengembangkan hipotesis dengan menganalisis pengaruh langsung dan tidak langsung antar variabel. Emosi Positif menjadi variabel mediasi dari visual merchandising dan pembelian impulsif. Penelitian terdahulu mengungkapkan adanya pengaruh dari visual merchandising terhadap munculnya emosi positif konsumen (Andani \& Wahyono, 2018; Devi \& Nurcaya, 2020; Fatma et al., 2020). Hal tersebut didukung juga penelitian terdahulu yang mengungkapkan bahwa emosi positif mampu menjadi variabel mediasi (Fazri et al., 2020; Sudarsono, 2017). Jadi, hipotesis yang diajukan adalah sebagai berikut:

H3: Emosi Positif memediasi hubungan antara visual merchandising dan pembelian impulsif.

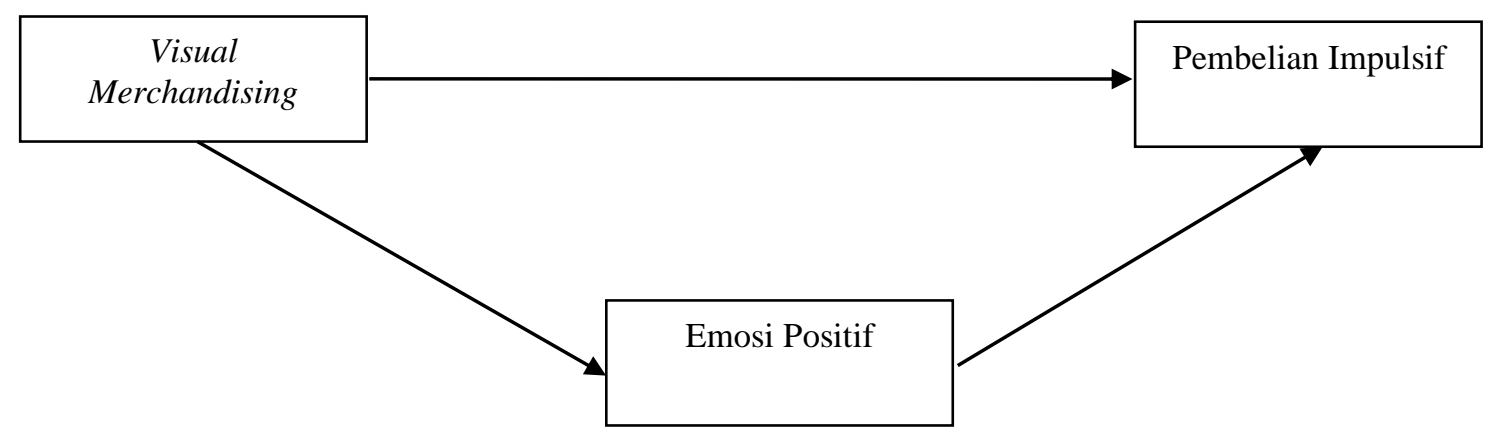

Gambar 1. Kerangka Konseptual

\section{METODELOGI PENELITIAN}

Sampel yang diambil yaitu pelanggan dari Toko Miniso yang berlokasi di Malang City Point Mall. Data pada penelitian ini yaitu primer dengan menggunakan kuesioner sebagai teknik pengumpulan data. Sampel diambil menggunakan teknik purposive sampling serta menggunakan kriteria sampel adalah pelanggan Miniso di Malang City Point Mall, selanjutnya sampel telah membeli produk Miniso pada 3 bulan sebelum penelitian dilaksanakan.

Seluruh item yang digunakan diukur menggunakan skala likert. Visual merchandising diukur menggunakan tiga belas item yang diadaptasi dari Sudarsono (2017) yang menjelaskan 4 dimensi yaitu etalase, formulir dalam toko, merchandising lantai dan papan nama promosi. Contoh item yang digunakan "terdapat tampilan logo miniso pada toko". Positive Emotion diukur menggunakan sembilan item yang diadaptasi dari (Devi \& Nurcaya, 2019) yang menjelaskan 3 dimensi yaitu (1) Pleasure (2) Arrousal dan (3) Dominance. Contoh Item yaitu "perasaan positif saat berbelanja di Miniso". Pembelian impulsif diukur menggunakan sepuluh item yang diadaptasi dari Utami (2014) yang menjelaskan 2 dimensi yaitu (1) Afective dan (2) Cognitive. Contoh item yaitu "muncul keinginan membeli di Toko Miniso secara tiba-tiba".

Data dianalisis menggunakan Structural Equation Model (SEM) dan pengujian hipotesis. SEM dianalisis menggunakan bantuan software SmartPLS 3.0. Pada penelitian ini peneliti menggunakan SEM untuk menguji hipotesis 1-3 dengan analisis jalur. Untuk mengetahui apakah visual merchandising berpengaruh signifikan pada pembelian impulsif, selanjutnya apakah visual 
merchandising berpengaruh signifikan pada emosi positif serta untuk menguji variabel emosi positif dalam memediasi hubungan antara visual merchandising dan pembelian impulsif.

\section{HASIL DAN PEMBAHASAN}

Menururt Sugiyono (2017) mengatakan bahwa populasi adalah tidak terbatas, jadi sebuah sampel sebanyak 100 orang diambil dari populasi berjumlah 5000 secara kasar mempunyai ketepatan estimasi yang sama dengan 100 sampel yang diambil dari 200 juta populasi. Sehingga jumlah sampel yang digunakan pada penelitian ini sebanyak 100 orang yang berpartisipasi pada penelitian ini. Responden yang berpartisipasi adalah konsumen dari Malang. Demografi responden secara ringkas disajikan tabel 1.

Tabel 1. Demographic Respondent

\begin{tabular}{|l|c|c|c|}
\hline Demographic & Description & Respondent & \% \\
\hline \multirow{4}{*}{ Jenis Kelamin } & Pria & 5 & $5 \%$ \\
\cline { 2 - 4 } & Wanita & 95 & $95 \%$ \\
\cline { 2 - 4 } & Jumlah & 100 & $100 \%$ \\
\cline { 2 - 4 } & $17-21$ Tahun & 79 & $79 \%$ \\
\cline { 2 - 4 } & $22-26$ Tahun & 18 & $1 \%$ \\
\cline { 2 - 4 } & $27-30$ Tahun & 1 & $2 \%$ \\
\cline { 2 - 4 } & $>30$ Tahun & 2 & $100 \%$ \\
\hline Status Pekerjaan & Jumlah & 100 & $95 \%$ \\
\cline { 2 - 4 } & Mahasiswa & 95 & $0 \%$ \\
\cline { 2 - 4 } & Pegawai Negeri & 0 & $0 \%$ \\
\cline { 2 - 4 } & Pegawai Swasta & 1 & $4 \%$ \\
\cline { 2 - 4 } & Wiraswasta & 0 & $100 \%$ \\
\cline { 2 - 4 } & Lainnya & 4 & $0 \%$ \\
\hline
\end{tabular}

Sumber: Data primer diolah, 2020

Responden perempuan berjumlah 95 orang dengan persentase $95 \%$ sedangkan responden laki-laki berjumlah 5 orang. Data diatas menggambarkan bahwa kebanyak dari responden merupakan wanita, hal ini disebabkan oleh mayoritas produk yang dijual di gerai Miniso merupakan produk untuk wanita seperti make up, aksesoris serta kebutuhan wanita lainnya. Selanjutnya, hal tersebut diperkuat dengan status pekerjaan responden mayoritas sebagai pelajar/mahasiswa sebanyak 95 orang atau 95\%. Kondisi tersebut dikarenakan target pasar dari Miniso merupakan pelajar atau mahasiswa yang sedang belajar di Kota Malang.

\section{Measurement Model}

Evaluasi dari measurement model memvalidasi hasil loading factor.Variabel dikatakan valid jika memiliki nilai loading factor diatas 0.50. Sementara nilai composite reliability sebaiknya sebesar $>0.70$ yang digunakan utuk mengukur reliabilitas. Seluruh variabel manifest terhadap variabel laten memiliki nilai loading factor $>0.50$ dan composite reliability $>0.70$ sehingga disimpulkan seluruh variabel laten memiliki reliabilitas yang baik. 
Tabel 2. Discriminant Validity

\begin{tabular}{|l|l|c|c|}
\hline \multicolumn{1}{|c|}{ Variable } & \multicolumn{1}{|c|}{ Indicator } & Loading Factor & Cut-Off \\
\hline Visual Merchandising & Window Display & .736 & .50 \\
& Floor Display & .502 & \\
& Promotional Signage & .848 & \\
\hline Impulse Buying & Affective & .899 & .50 \\
& Cognitive & .641 & \\
\hline Positive Emotion & Pleasure & .756 & .50 \\
& Arousal & .580 & \\
& Dominance & .637 & \\
\hline
\end{tabular}

Sumber: Data primer diolah, 2020

Table 3. Reliability

\begin{tabular}{|l|c|c|}
\hline \multicolumn{1}{|c|}{ Variable } & Composite Reliability & Conclusion \\
\hline Visual Merchandising & 0.752 & Reliable \\
\hline Impulse Buying & 0.798 & Reliable \\
\hline Positive Emotion & 0.745 & Reliable \\
\hline
\end{tabular}

Sumber: Data primer diolah, 2020

\section{Structural Model}

Model struktural dievaluasi menggunakan nilai $\mathrm{R}$ square dari dependent variabel serta nilai $t$-statistic dari masing-masing jalur. Pengujian hipotesis diuji menggunakan metode boothstrapping untuk memperoleh nilai koefisien jalur. Sesuai dengan hasil uji hipotesis maka dapat di interpretasikan 1) Visual merchadising tidak dapat meningkatkan pembelian impulsif; 2) Emosi positif meningkatkan pembelian impulsif; dan 3) Emosi positif mampu menjadi variabel mediasi antara hubungan visual merchandising dan pembelian impulsif. Selanjutnya disajikan hasil ringkasan uji hipotesis sebagai berikut.

Tabel 4. Ringkasan Pengujian Hipotesis

\begin{tabular}{|l|c|c|c|}
\hline \multicolumn{1}{|c|}{ Hipotesis } & Original Sample & t-statistic & Kesimpulan \\
\hline $\begin{array}{l}\text { Visual Merchandising } \rightarrow \\
\text { Pembelian Impulsif }\end{array}$ & .253 & 1.741 & Ditolak \\
\hline $\begin{array}{l}\text { Visual Merchandising } \rightarrow \text { Emosi } \\
\text { Positif }\end{array}$ & .296 & 2.611 & Diterima \\
\hline $\begin{array}{l}\text { Emosi Positif } \rightarrow \text { Pembelian } \\
\text { Impulsif }\end{array}$ & .352 & 2.235 & Diterima \\
\hline
\end{tabular}


Tidak seperti yang diperkirakan, hasil penelitian menunjukkan bahwa visual merchandising tidak berpengaruh pada sebuah pembelian impulsif konsumen, sehingga hal tersebut membuktikan bahwa hipotesis pertama ditolak. Lebih jauh, penelitian menggambarkan dengan penempatan serta pengaturan tempat produk yang menarik secara nyata tidak menarik bagi pelanggan yang datang ke toko maupun yang melihat di halaman beranda pada aplikasi belanja online. Penelitian ini membuktikan secara umum berkenaan dengan penataan rak dan produk di Miniso secara empiris terbukti tidak mampu meningkatkan kuantitas penjualan yang signifikan, hal ini juga terlihat dari adanya pembelian impulsif secara tiba-tiba dari pelanggan. Peneliti berasumsi masih diperlukan untuk menganalisis lebih dalam mengenai variabel lain yang dapat secara signifikan meningkatkan kuantitas penjualan di Miniso yang berada di Malang City Point Mall.

Selanjutnya pada hipotesis 2 , hasil penelitian menunjukkan secara empiris bahwa emosi positif secara signifikan mempengaruhi pembelian impulsif, sehingga hipotesis kedua diterima. Penelitian ini memperkuat pendapat dari Anggriawan et al. (2016) yang menyatakan jika pelanggan sudah memiliki emosi positif dalam dirinya, akan berdampak pada pembelian impulsif konsumen. Beberapa penelitian terdahulu telah membahas tentang visual merchandising yang berpengaruh pada munculnya emosi positif (Fatma 2019; Andani dan Wahyono, 2018; Devi dan Nurcaya 2020).

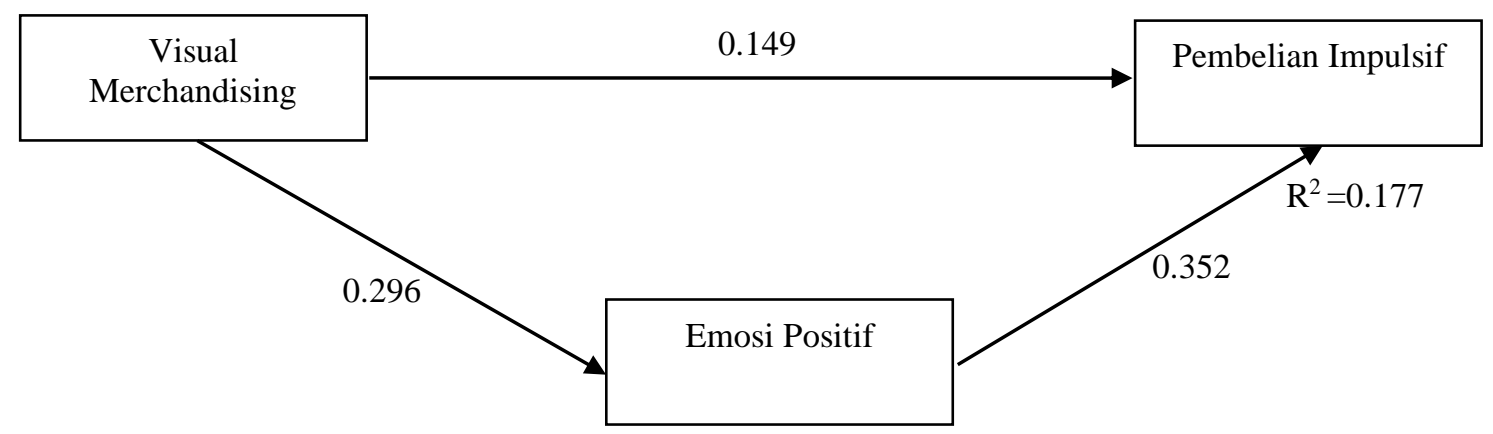

Gambar 2. Hasil Analisis Jalur

Berdasarkan gambar 2 juga menggambarkan bahwa terdapat pengaruh signifikan antara visual merchandising pada pembelian impulsif melalui emosi positif, sehingga, hipotesis ketiga diterima. Penelitian ini mendukung beberapa penelitian lain dari Sudarsono (2017) dan Fazri (2020). Emosi positif adalah suasana yang tercipta ketika berbelanja. Pengalaman pelanggan dapat menghasilkan perasaan positif secara otomatis berdampak pada pembelian. Namun, apabila pengalaman pelanggan tidak baik maka emosi yang muncul cenderung negatif yang mengakibatkan tidak tertarik dalam melakukan aktivitas pembelian. Pembelian impulsif adalah sebuah aktivitas membeli dengan spontan tanpa perencanaan yang matang. Pembelian impulsif sebagian besar muncul karena adanya rangsangan beberapa sebab saat pelanggan datang ke gerai, seperti emosi yang baik, faktor internal dan eksternal yang mendukung sehingga membuat pelanggan bersedia melakukan pembelian. 


\section{PENUTUP}

\section{Simpulan}

Penelitian ini diselenggarakan kepada pelanggan Miniso yang berada di Malang City Point Mall dengan melibatkan 100 orang. Peneliti memperoleh hasil yaitu visual merchandising yang tidak berpengaruh signifikan kepada pembelian impulsif yang berlawanan dengan kajian dari Diah \& Sulistyowati (2020), Mutiah \& Munir (2018), Nurudin (2020). Sehingga semakin baik visual merchadising, hal tersebut tidak dapat mempengaruhi sebuah penjualan. Dalam penelitian ini, ditemukan hal yang berbeda dengan teori mengenai visual merchandising, yang menggambarkan bahwa konsumen tidak menjadikan visual merchandising sebagai motivasi dalam melakukan pembelian. Perbedaan hasil penelitian ini dikarenakan konsumen beranggapan bahwa mereka tidak memerlukan adanya visual merchandising dalam memutuskan pembelian, terlebih lagi dengan adanya pandemi ini yang menerapkan peraturan dari pemerintah mengenai pembatasan kegiatan masyarakat dan mall ditutup. Dalam hasil selanjutnya, ditemukan bahwa visual merchandising berpengaruh terhadap emosi positif. Penataan toko yang rapi dan menarik dapat menimbulkan perasaan positif pelanggan saat berkunjung ke Miniso. Hal ini menggambarkan bahwa tata letak toko mempengaruhi kenyamanan dalam berbelanja. Selanjutnya emosi positif mampu menjadi variabel mediasi hubungan antara visual merchandising kepada pembelian impulsif. Dalam memasukkan emosi positif membuat visual merchadising yang secara langsung tidak berpengaruh signifikan menjadi signifikan. Hal ini dapat disimpulkan bahwa emosi positif mampu menjadi variabel mediasi sempurna atau full mediation.

Tentunya penelitian ini memiliki keterbatasan penelitian yaitu hanya dilakukan pada satu gerai saja sehingga hasil penelitian tidak dapat digeneralisir pada konsumen di kota lain serta gerai yang lain. Kemudian penelitian ini hanya menggunakan satu variabel mediasi, sehingga penelitian selanjutnya diharapkan dapat membandingkan konsumen dari beberapa gerai dari kota lain serta menambahkan variabel mediasi lain agar hasil penelitian dapat lebih dalam mengenai pemahaman tentang pembelian impulsif.

Implikasi praktis dapat dijelaskan bahwa adanya emosi positif akan turut meningkatkan pembelian impulsif, sehingga elemen emosi positif harus ditampilkan di dalam toko. Munculnya emosi positif dapat dilakukan dengan cara memaksimalkan kondisi internal gerai seperti faktor kenyamanan, keindahan dan tata letak yang menarik. Selanjutnya, studi empiris dari penelitian ini menunjukkan bahwa visual merchandising dapat meningkatkan pembelian impulsif yang diperkuat dengan adanya perasaan emosi positif yang muncul akibat pengalaman yang baik ketika berbelanja di dalam toko maupun ketika berbelanja secara online melalui aplikasi belanja yang telah disediakan oleh manajemen Miniso.

\section{Saran}

Bagi pemilik toko Miniso yang berada di Malang City Point Mall dapat disarankan untuk menerapkan alternatif strategi khususnya pada masa pandemi covid-19 dengan tujuan kenyamanan dan kemanan pelanggan. Lebih lanjut, pihak manajemen Miniso yang berada di Mall City Point Malang juga perlu mengevaluasi segala strategi yang telah dijalankan selama ini dalam rangka menjaga emosi positif pelanggan ketika berada di gerai serta memaksimalkan tata letak gerai supaya konsumen tidak mudah bosan serta terus untuk tertarik untuk melakukan sebuah pembelian secara online. 


\section{REFERENSI}

Andani, K., \& Wahyono, W. (2018). Influence of Sales Promotion, Hedonic Shopping Motivation and Fashion Involvement Toward Impulse Buying through a Positive Emotion. Management Analysis Journal, 7(4), 448-457.

Anggriawan, B., Suardana, I. W., \& Sendra, I. M. (2016). Analisis faktor yang mempengaruhi impulse buying wisatawan domestik terhadap produk pariwisata di Biro Perjalanan Wisata Bali. Jurnal IPTA (Industri Perjalanan Wisata), 4(1), 101-106.

BBM, R. J. S. (2013). Visual Merchandising Attraction. Gramedia Pustaka Utama.

Bismo, A., Putra, S., Sarjono, H., \& Nasrul, L. (2020). Effect of Functional Convenience and Representational Delight on Positive Emotional Effect and Impulse Buying of Discount Group Site Users in Indonesia. Pertanika Journal of Social Sciences \& Humanities, 28(2).

Dey, D. K., \& Srivastava, A. (2017). Impulse buying intentions of youngconsumers from a hedonic shopping perspective.Journal of IndianBusiness Research,9(4), 266-282.

Devi, D. A. C., \& Nurcaya, I. N. (2020). Peran Positive Emotion Memediasi Store Atmosphere Terhadap Impulse Buying Di Beachwalk Kuta Bali. E-Jurnal Manajemen, 9(3), 884903.

Deviana. D, Ni P S., Giantari, I G A K. (2016). Pengaruh Shopping Lifestyle dan Fashion Involvement Terhadap Impulse Buying Behavior Masyarakat di Kota Denpasar. EJournal Manajemen Unud, 5(8). hal. 5264-5273.

Diah Anggraini, I., \& Sulistyowati, R. (2020). Pengaruh Visual Merchandising Dan Sore Atmosphere Terhadap Perilaku Impulse Buying (Studi Kasus Pada Konsumen MINISO Di Surabaya). Jurnal Pendidikan Tata Niaga (JPTN), 8(1).

Fatma, R. P., Rahmawati, R., \& Tricahyadinata, I. (2020). Pengaruh Visual Merchandising Terhadap Positive Emotion dan Impulse Buying Pada Konsumen Zoya Lembuswana Samarinda. Jurnal Ilmu Manajemen Mulawarman (JIMM), 4(4).

Fazri, A. F., Arifin, R., \& Primanto, A. B. (2020). Pengaruh Visual Merchandising, Potongan Harga, Kualitas Layanan, Dan Store Atmosphere Terhadap Impulse Buying Melalui Emosi Positif Sebagai Variabel Mediasi Pada Pembeli Toko Paradise (Studi Kasus Pada Masyarakat Kelurahan Sisir). Jurnal Ilmiah Riset Manajemen, 9(08).

Firdayanti, N., Ramdan, A. M., \& Sunarya, E. (2020). Pengaruh Visual Merchandising Dan Product Assortment Terhadap Impulse Buying (Survei Pada Konsumen Rabbani Kota Sukabumi). E-Jurnal Ekonomi Dan Bisnis Universitas Udayana, 391-404.

Husnain, M., \& Waheed Akhtar, M. (2016). Impact of branding on impulsebuying behavior: Evidence from FMCG's sector Pakistan. International Journal of Business Administration,7(1), 59-68.

Kandampully, J., Zhang, T. C., \& Jaakkola, E. (2018). Customer experience management in hospitality: A literature synthesis, new understanding and research agenda. International Journal of Contemporary Hospitality Management.

Kertiana, I. K. D., \& Artini, I. G. A. K. S. (2019). Pengaruh Visual Merchandising, Atmosfer Toko, Dan Display Produk Terhadap Impulse Buying Pelanggan Ramayana Denpasar. E-Jurnal Manajemen, 8(11), 6533-6557.

Kinasih, I. A. D., \& Jatra, I. M. (2018). Peran Emosi Positif Memediasi Pengaruh Fashion Involvement Dan Hedonic Consumption Tendency Terhadap Impulse Buying. E-Jurnal Manajemen, 7(6), 3258-3290. 
Liao, C., To, P.-L., Wong, Y.-C., Palvia, P., \& Kakhki, M. D. (2016). The impact of presentation mode and product type on online impulse buying decisions. Journal of Electronic Commerce Research, 17(2), 153.

Lim, B., Ling, P., \& Yazdanifard, R. (2015). What internal and external fac-tors influence impulsive what internal and external factors influence.Global Journal of Management and Business Research: E Marketing,15(5), 2-9.

Mutiah, I., Parawansa, D., \& Munir, A. R. (2018). Pengaruh Visual Merchandising, Display Product, Dan Store Atmosphere Terhadap Perilaku Impulse Buying (Studi Kasus: Konsumen Matahari Department Store Di Kota Makassar). Hasanuddin Journal of Applied Business and Entrepreneurship, 1(2), 88-103.

Nurudin, N. (2020). Analysis of the Effect of Visual Merchandising, Store Atmosphere and Sales Promotion on Impulse Buying Behavior. Journal of Digital Marketing and Halal Industry, 2(2), 167-177.

Pancaningrum, E. (2017). Visual Merchandise Dan Atmosfer Toko: Pengaruhnya Terhadap Keputusan Pembelian Impuls. Jurnal Ilmu Ekonomi Dan Pembangunan, 17(1).

Pramestya, N. L. P. U. M., \& Widagda, I. J. A. (2020). The Role of Positive Emotion Mediates Fashion Involvement on Impulse Buying. American Journal of Humanities and Social Sciences Research (AJHSSR), 4(9), 1-8.

Sari, D. A. T., \& Suryani, A. (2014). Pengaruh Merchandising, Promosi dan Atmosfir Toko Terhadap Impulse Buying. E-Jurnal Manajemen Universitas Udayana, 3(4).

Sugiyono. (2017). Metode Penelitian Kuantitatif, Kualitatif, dan R\&D. Bandung : Alfabeta, CV

Soodan, V., \& Pandey, A. C. (2016). Influence of emotions on consumer buying behavior. Journal of Entrepreneurship, Business and Economics, 4(2), 163-181.

Shirmohammadi, M., Ghane, N., \& Ebrahimi, M. R. (2015). Investigating and prioritizing the effective factors on internet impulse buying behavior of customers (case study: Discount group sites). Business and Management, 7(3), 275-290.

Sudarsono, J. G. (2017). Pengaruh visual merchandising terhadap impulse buying melalui positive emotion pada zara surabaya. Jurnal Manajemen Pemasaran, 11(1), 16-25.

Utami, C.W. (2014). Manajemen ritel : Strategi dan implementasi operasional bisnis ritel modern di Indonesia. Jakarta : Salemba Empat 